afarensis seems almost trivial in comparison to her more compelling and dramatic critical assessment of Darwin, Huxley and Haeckel's struggles with more herculean evolutionary themes. I would be fascinated to see Landau dissect contemporary icons of palaeoanthropology with the same surgical blades she uses on our idols of the past.

Science can be conveniently divided into three classes: the 'soft sciences' such as sociology and political science, the 'hard sciences' such as physics and chemistry and then the 'really difficult sciences' such as palaeoanthropology. Narratives of Human Evolution is a literate, thought-provoking explication of this really difficult science. I would add only one further thought to Landau's story. She notes that Huxley never did bridge that gap between the apes and humanity with a missing link. Maybe that is because the missing link is man.

Glenn C. Conroy is in the Department of Anatomy and Anthropology, Washington University Medical School, St Louis, Missouri 63110, USA

\section{Theories for everything}

\section{A. Hallam}

Extinction: Bad Genes or Bad Luck? By David M. Raup. Norton: 1991. Pp. 210. $\$ 19.95$.

The Miner's Canary: Unravelling the Mysteries of Extinction. By Niles Eldredge. Simon and Schuster: 1991. Pp. 246. \$20.

AlTHOUGH argument persists about the extent to which Darwin was a gradualist when it came to modes of speciation, with The Origin of Species being quoted like so much Holy Writ, there is no room for doubt about his views on the relative importance of biotic as opposed to physical causes in promoting extinction. "Species are produced and exterminated by slowly acting causes .... and the most important of all causes of organic change is one which is almost independent of altered . . . physical conditions, namely the mutual relation of organism to organism - the improvement of one organism entailing the improvement or the extermination of others". This 'struggle for existence' view has been accepted uncritically by generations of evolutionary biologists, and is well expressed in Van Valen's famous Red Queen hypothesis, named after Lewis Carroll's character who found that, in her sort of country, it took all the running one could do to stay in the same place.
Thus, in the darwinian view, the biologically 'superior' mammals would have progressively outcompeted the dinosaurs through the course of the Mesozoic era, until dinosaurs eventually became extinct. It is now clear that this did not happen - mammalian radiations had to await the disappearance of the dinosaurs together with many contemporary terrestrial and marine organisms, a disappearance caused by mass extinction resulting from drastic environmental deterioration at the end of the Cretaceous period. Any competition between the dinosaurs and mammals must therefore have been pre-emptive rather than displacive, the key requirement being to be the first to occupy the ecological niche. This pattern of change appears to be characteristic of the fossil record as a whole, with episodic mass extinctions clearing the decks, as it were, for the radiation of new organic groups. In Raup's words, extinction appears to have been more a matter of bad luck than bad genes, because normal darwinian finely tuned adaptations would often have been a poor defence against a rare environmental catastrophe.

These two books on extinction by leading US palaeontologists are aimed at a wide audience and demand little technical knowledge. Both books have considerable merits but are very different in their treatment of the subject, reflecting the different aptitudes and interests of their authors. Raup's great strength is his skill in handling data statistically and his ability to make incisive points on the basis of this quantitative approach. $\mathrm{He}$ presents a penetrating discussion of randomness, based on such diverse topics as the 'gambler's ruin' problem and the skewed distributions ubiquitous in nature, and uses this to argue cogently for rarity being the main factor promoting extinction. He makes a pertinent comparison of mass extinctions with more familiar natural phenomena such as earthquakes and floods, with the events of greatest intensity being the least frequent. His disturbingly named "kill curve" depicts the average number of species killed for a series of waiting times, and hence tells us the average likelihood of a given event in a given length of time; needless to say, mass extinctions fall high on the curve.

The title of Eldredge's book refers to the canaries used by miners as early warning systems for poisonous gases. The recent decline of migrating songbirds fits the same role on a global scale, and is clearly a measure of habitat destruction, which in his view has always been the main cause of extinction. Eldredge writes as lucidly as Raup, but his style is less dry and more eloquent, and his book is richer than Raup's in biological examples. He outlines the reasons for the diversity of the organic world, indicating that rates of speciation and extinction are higher in specialist forms: the higher diversity of the tropics is largely a consequence of finer nichepartitioning among more stenotopic organisms. Mass extinctions are in his view dramatic events that extended over millenia or longer, and are not normally the consequence of geologically instantaneous catastrophes.

In reviewing the possible physical causes of mass extinctions in the prehuman past, neither author is dogmatic and both freely admit to the continuing uncertainty and dispute within the scientific community. Because Raup believes that nature would have great difficulty eliminating species over large areas, he favours the crash of asteroids or comets into the Earth as the cause of not just mass extinction, but background extinction as well. This is, to my mind, a truly astonishing conclusion, being based on virtually no evidence apart from the pronounced iridium anomalies and shocked quartz at the Cretaceous/ Tertiary boundary, which is the only reason why the impact story is taken seriously at all. Eldredge takes what I believe to be the geologically more reasonable view, for which there is much evidence from the stratigraphic record. In this view, important environmental changes bound up with events confined to our planet are responsible for mass extinctions. He sees no need to invoke deus ex machina of extraterrestrial events except for the Cretaceous/ Tertiary boundary extinctions; even here, any impact was probably no more than a coup de grâce to elements of an already perturbed biosphere.

Although he does not discount sealevel change, Eldredge favours climatic deterioration as the most important extinction-inducing factor. I think that he overstates the case. Whereas falling temperature appears to have been implicated in the Cenozoic and late Ordovician extinctions, the evidence for other times ranges from poor or equivocal to nonexistent. Further, there is a strong correlation between marine extinction and global sea-level change: relatively sudden falls led to extensive regression of epicontinental seas, and, probably more importantly, sharp rises were associated with the spread of anoxic waters. Both could have caused devastating loss of habitat area. Despite the strong evidence for these phenomena, Raup does no more than mention them in passing, whereas Eldredge ignores them completely. In particular, these events get around the objection made by Raup that the pronounced regressions of the Quaternary period do not correlate with important extinction episodes, and hence the case 
for sea-level change is not supported. The Quaternary world, with its extensive polar icecaps and well-oxygenated ocean, is an unreliable guide to most of Phanerozoic time.

It is clear that we are witnessing a mass extinction that is almost entirely the result of human activities. Eldredge is surely right that this is largely the consequence of habitat destruction rather than direct slaughter, but the consequences are nonetheless dire for cur own species as well as others. Conservation is more than just a matter of saving the odd squirrel species. To echo the words of a recent disenchanted US Secretary of the Interior, it involves the management of entire ecosystems, which falls in the sphere of politics as much as science.

A. Hallam is in the School of Earth Sciences, University of Birmingham, Birmingham B15 $2 \pi$, UK.

\section{Sceptical inquiries of old}

\section{Jeremy A. Sabloff}

Fantastic Archaeology: The Wild Side of North American Prehistory. By Stephen Williams. University of Pennsylvania Press: 1991. Pp.432. \$28.95, £27.50 (hbk); $\$ 14.95$, £11.95 (pbk).

NEARLY three decades ago, the late Robert Wauchope, in his brilliant book Lost Tribes and Sunken Continents (University of Chicago Press, 1962), wrote that in response to the widespread popularity of the work of pseudoscientists, "the average professional anthropologist cannot or will not write the kind of book that people in great numbers will want to read". Fortunately, in the years since Wauchope made that damning statement, a growing number of practising scientists have entered the public fray. Fantastic Archaeology by Stephen Williams, Peabody Professor of North American Archaeology and Ethnology at the Peabody Museum, Harvard University, is a superb example of this recent trend. Engagingly written, the book's clear discussion of a variety of archaeological controversies is readily accessible to the general reader and should be of interest to both lay people and professional scholars alike.

More than any other discipline, archaeology has been unsuccessful in convincing the public at large that there is a clear line between the writings and conclusions of professional scholars and amateur dabblers. Although Williams does not closely examine the cultural reasons for this problem nor the huge

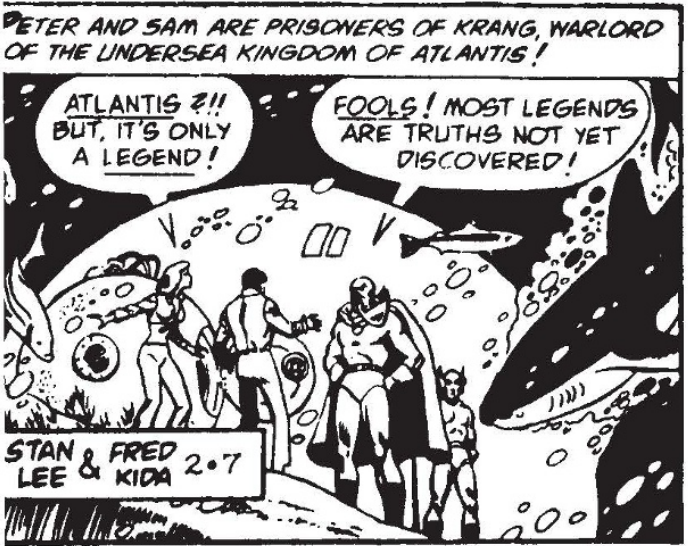

328

origins of North American archaeology and the main intellectual debates of the nineteenth century, Williams forges on to examine a host of fascinating and controversial topics, including famous frauds such as the Grave Creek Stone, the Cardiff Giant and the Davenport Tablets; Constantine Rafinesque and the Walam Olum legend; claims for early Ice Age finds; the supposed lost islands of Atlantis and $\mathrm{Mu}$ and their advocates, particularly Ignatius Donnelly, Helena Blavatsky and the Theosophical Society, and James Churchward; archaeology and religion; alleged Viking finds such as the Kensington Stone and the Newport Tower; assertions of Asian influences on ancient North America with special attention to the writings of Harold Gladwin; the 'decipherments' of averred prehistoric inscriptions by writers such as Barry Fell; and the pronouncements of psychics such as Edgar Cayce, Jeffrey Goodman and Stephen Schwartz.

Williams concludes with a synopsis of does offer one of the best descriptions

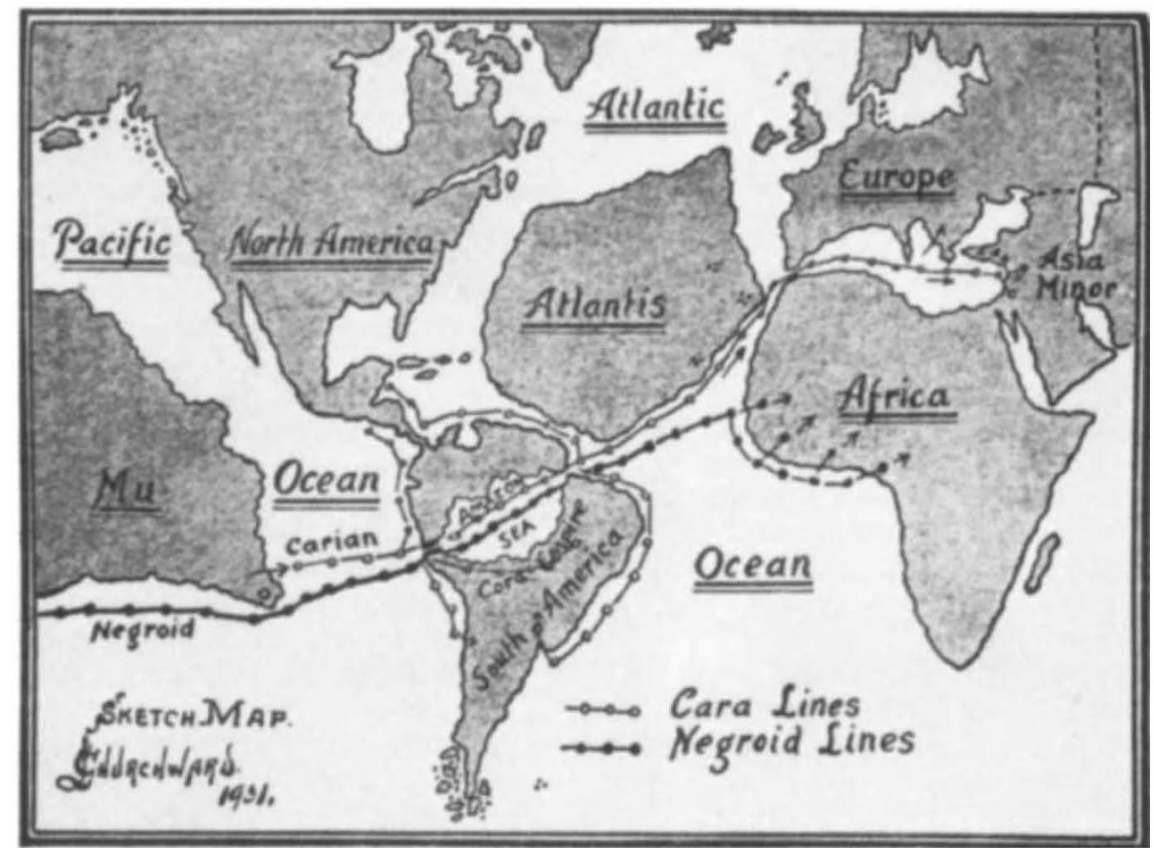

Sunken continents - Churchward's map of Atlantis and Mu, showing Mu's lines of influence on the whole picture of "man's advent on Earth", as he put it.

available of the differences between archaeological and fantastic accounts of various aspects of North American prehistory. He defines fantastic archaeology at the start as "those alternative views of the past that use data and interpretation that will not stand close scrutiny" and proceeds to offer a useful and tolerant overview of its nature and practitioners. The procedures of these purveyors of myth and fantasy are tellingly contrasted with those of trained archaeologists and the latter's use of the scientific method. In addition, the general criteria by which archaeological hypotheses (or assertions) of all stripes can be evaluated are concisely outlined.

Then, after a lucid discussion of the what he calls "the real fantasy", the scientifically reconstructed history of the cultural achievements of the Native American inhabitants of North America. $\mathrm{He}$ maintains that the latter story has as many exciting and intriguing elements as the concocted histories of the pseudoscientific cranks. Archaeologists must strive to make the public aware of this story, Williams convincingly argues, while continuing to be "skeptical inquirers after knowledge and relentless foes of fraud and unreason".

Jeremy A. Sabloff is in the Departments of Anthropology and the History and Philosophy of Science, University of Pittsburgh, Pittsburgh, Pennsylvania 15260, USA. 